(C) [2010] IEEE. Reprinted, with permission, from [Yi Wang, Jianguo Zhu and Youguang Guo, A Comprehensive Analytical Mathematic Model for Permanent-Magnet Synchronous Machines Incorporating Structural and Saturation Saliencies, Magnetics, IEEE Transactions on (Volume:46, Issue: 12 ), Dec. 2010]. This material is posted here with permission of the IEEE. Such permission of the IEEE does not in any way imply IEEE endorsement of any of the University of Technology, Sydney's products or services. Internal or personal use of this material is permitted.

However, permission to reprint/republish this material for advertising or promotional purposes or for creating new collective works for resale or redistribution must be obtained from the IEEE by writing to pubs-permissions@ieee.org. By choosing to view this document, you agree to all provisions of the copyright laws protecting it 


\title{
A Comprehensive Analytical Mathematic Model for Permanent Magnet Synchronous Machines Incorporating Structural and Saturation Saliencies
}

\author{
Yi Wang, Jianguo Zhu, Senior Member, IEEE, and Youguang Guo, Senior Member, IEEE
}

\begin{abstract}
This paper introduces a new method to model the permanent magnet synchronous machines (PMSMs) with saliencies due to the salient structure and magnetic saturation. Two parameters are defined to indicate these saliencies, i.e. the structural saliency ratio $\left(K_{s t r}\right)$ and the saturation saliency ratio $\left(K_{\text {sat }}\right)$. To verify the nonlinear model, a real PMSM is tested and numerically simulated. The nonlinear inductance matrix is deduced and expressed by a nonlinear function regressed from the experimental data. The simulation and experimental results agree well with each other.
\end{abstract}

Index Terms-Permanent magnet synchronous machines, mathematic modeling, structural saliency, saturation saliency.

\section{NOMENCLATURE}

Symbols and Abbreviations

$\begin{array}{ll}\Phi_{t}, \Phi_{f} & \text { Total and rotor flux vectors } \\ i_{t}^{*}, i_{f} & \text { Total and rotor equivalent currents } \\ v_{\alpha}, v_{\beta} & \text { Stator } \alpha \text { - and } \beta \text {-axis voltages } \\ i_{\alpha}, i_{\beta} & \text { Stator } \alpha \text { - and } \beta \text {-axis currents } \\ \lambda_{\alpha}^{*}, \lambda_{\beta}^{*} & \text { Projected flux linkages on } \alpha \text {-and } \beta \text {-axis } \\ v_{d}, v_{q} & \text { Rotor } d \text { - and } q \text {-axis voltages } \\ i_{d}, i_{q} & \text { Rotor } d \text { - and } q \text {-axis currents } \\ \lambda_{d}^{*}, \lambda^{*} & \text { Projected flux linkages on } d \text { - and } q \text {-axis. } \\ R & \text { Stator resistance } \\ K_{\text {str }} & \text { Structural saliency ratio } \\ K_{\text {sat }} & \text { Saturation saliency ratio } \\ \text { LRRSS } & \text { Least Relative Residual Sum of Square }\end{array}$

\section{INTRODUCTION}

$\mathrm{T}$ HE permanent magnet (PM) electrical machines, e.g. the permanent magnet synchronous machine (PMSM), have found wide applications due to their high-power density (compactness), high efficiency, ease of control, high torque-to-inertia ratio, and high reliability.

The traditional PMSM model is based on the linear magnetic property assumption that the inductance of the stator winding is a constant value for different stator currents. The linear model functions reasonably well in describing the energy conversion and the torque generation inside a PMSM. The widely used field oriented control (FOC) and direct-torque control (DTC) methods were developed based on this linear model and achieved good control performance. A lot of efforts then have been made to improve the PMSM drive performance from the aspects of power electronics, control theory or computing techniques [1]-[3]. However, the application of PMSMs is limited because of the unavoidable rotor-position sensor, which not only increases the system cost, but also perhaps more importantly reduces the system reliability.

In recent years, numerous papers have been published that address the sensorless control methods to eliminate the mechanical position and/or speed sensors. In general, they can be classified as rotating voltage vector injection method [4] [5] and pulsating voltage vector injection method [6] [7]. However, there is not an analytical solution for initial rotor position detection and sensorless drive method developed because of the lack of accurate nonlinear machine model incorporating the magnetic saliencies. The experimental trial and error method is commonly employed to develop and verify the sensorless drive schemes. On the other hand, the machine state observers developed based on simplified mathematic model would lead to errors on the control side.

Therefore, an analytical nonlinear model for PMSM is required, in which the saturation effect is incorporated. The magnetic saturation effect in electrical machines has been proved and studied in [8-10]. Brown incorporated this saturation effect in the generalized equation of induction machines [11] and then the inductances were recognized as function of the magnetization currents for synchronous machines [12]. However, the inductance function was not expressed. Then the drive strategies for SRM [13] and induction machines [14] [15] were investigated considering the saturation effect in order to develop high performance controller.

The reported magnetic analytical models [16] [17] are not applicable, because the desirable model should be developed in terms of machine electrical equations and could be further applied to derive the drive solutions. In [18], an integrated finite element method (FEM) based machine model was developed with the machine drive system. This model could achieve faster 
simulation speed than traditional FEM models. However, the saturation effect was not incorporated.

Considerations were also taken to calculate the machine inductance variation associated with the saturation effect. In [19], a new method was reported to identify the PMSM parameters. The saturation effect was considered as well. Later in [20], the inductances $L_{d}$ and $L_{q}$ variations were numerically modeled and regressed by using recursive least square (RLS) method to reduce the torque ripples. However, the saturation effect or the inductance variation was not analytically expressed and those methods did not consider the nonlinear cross-saturation effect between orthogonal axes.

The cross-saturation effect was discovered in 1980's and it is proved that the cross-saturation exists if the magnetic motive force distributions are assumed to be sinusoidal [21]. Later, Melkebeek [22] proved that the mutual-inductances in the dynamic analysis of saturated machines must be reciprocal not only for a uniform air-gap machine but also for a salient-pole-type machine. In [23], the mutual-inductance between the orthogonal $d$ - and $q$-axes was tested from a switch reluctance machine (SRM). Later this mutual-inductance was calculated for PMSM by Meessen based on FEM [24]. In [25], a high frequency signal was injected to the stator windings to measure the cross-coupling inductance between $d$ - and $q$-axes. The measured results were verified by using FEM as well. It is proved that the estimated cross-coupling inductance could be applied to reduce the reported rotor position detection errors for sensorless drive schemes, but it was not expressed by using the machine parameters and could not be utilized to develop new sensorless algorithms.

For the analytical machine model, Melkebeek proposed a nonlinear inductance model [26], in which the nonlinear inductances were defined from coenergy and flux point of view. An analytical expression of the inductance matrix of synchronous machine was carried out. A parameter was defined to indicate the operation point of the machine according to the magnetization curve. This model was successful and later applied to develop rotor-position estimator for synchronous machine [27]. However, this model does not decouple the structural and saturation saliencies and requires very accurate magnetization-curve data to model the saturation effect. It has not been applied to analytically access the drive schemes.

On the other hand, FEM calculations were applied to sensorless drives of PMSM in order to investigate the drive performance in terms of magnetic field [28] [29]. In [30], an initial rotor position detection method was proposed based on transient FEM. Both the rotor position and the rotor polarity could be identified based on DC pulse injection method. However, the computing cost of FEM based scheme is too large to be applied for the rotating performance simulation. A compromise is desirable to enable accurate and fast PMSM performance simulation. Yan and Zhu [31] proposed a numerical inductance model which incorporates the nonlinear saturation effect, by using which, the machine nonlinear behavior is involved in the simulation. However, the model was built based on a specific permanent magnet machine prototype and cannot be extended to other machines.

In this paper, the nonlinear saturation effect, as well as the structural saliency, is incorporated and expressed in the new analytical machine model. Two factors, the structural saliency ratio $\left(K_{\text {str }}\right)$ and the saturation saliency ratio $\left(K_{\text {sat }}\right)$, are defined to indicate the extent of magnetic saliencies. The mathematic model of PMSM is derived in both the stator and rotor reference frames. The nonlinear inductance matrix is expressed as a function of the stator current and the rotor position. A surface mounted PMSM (SPMSM) is chosen as the prototype to verify the machine model. The inductance curves of the SPMSM are measured and modeled by the nonlinear inductance matrix in the form of functions of rotor position and stator current. Then the proposed mathematic model is applied to estimate the machine inductance and compared with the measured curves. Both the self- and mutual-inductances of the stator $\alpha-\beta$ reference frame are estimated and plotted. Finally, experiments are carried out to verify the proposed model. The simulated machine performances are compared with the experiment results. The comparison shows that the proposed model is an accurate method to model and analyze the PMSM nonlinear behaviors. Furthermore, it could be used to develop the sensorless drive schemes analytically.

\section{MagnetiC SALIENCIES AND INDICATORS}

The magnetic saliencies in a PMSM could be classified as the structural saliency that mainly comes from the salient structure, and the saturation saliency induced by the magnetic saturation inside the core [31]. For a given PMSM, these saliencies could be decoupled since the saturation is due to the nonlinear magnetic property of the core while the structural saliency is not related to the magnetic nonlinearity [32].

In a PMSM, the total flux linking the stator windings can be attributed to two sources - the rotor permanent magnets and the stator AC currents. Because of the nonlinear saturation effect, the total flux cannot be separated into flux spatial vectors due to the permanent magnet and stator current, respectively.

In order to express the extent of magnetic saliencies, two parameters, $K_{\text {str }}$ and $K_{\text {sat }}$, are defined for the structural and saturation saliencies, respectively.

\section{A. Structural Saliency Ratio}

The structural saliency is always prefixed for a PMSM when it has been designed. It is formed by the structure of the machine including rotor magnet and usually easy to obtain from the unbalanced $d$ - and $q$-axis inductances in the machine model.

To express and analyze the structural saliency, the average linear inductance and $K_{\text {str }}$ are respectively defined as

$$
\begin{aligned}
& L_{a v}=\frac{L_{d}+L_{q}}{2} \\
& K_{\text {str }}=\frac{L_{d}-L_{q}}{L_{d}+L_{q}}
\end{aligned}
$$


where $L_{d}$ and $L_{q}$ are respectively the $d$ - and $q$-axis inductances without excitation in the stator. For the excited condition, $L_{d d}$ and $L_{q q}$ are defined later as the $d$ - and $q$-axis inductances.

In the traditional SPMSM model, $K_{\text {str }}$ is usually assumed to be zero because the structural saliency is very small. In this paper, it is considered and expressed.

\section{B. Saturation Saliency Ratio}

The saturation saliency is caused by the saturation effect of the stator core and exists in both interior PMSMs (IPMSMs) and SPMSMs. It is usually discussed for SPMSM because it is the main saliency inside an SPMSM, where the structural saliency is always ignorable.

As discussed above, the saturation of the stator core mainly takes place in the direction of the total flux vector. As a result, the inductance in this direction can be treated as a function of the equivalent total current. It is not a constant value as defined in the traditional PMSM model. Based on the saturation curve, $K_{\text {sat }}$ is then defined as the difference ratio between the chord-slope inductance and the tangent-slope inductance.

$$
K_{\text {sat }}\left(i_{0}\right)=\frac{\frac{\lambda\left(i_{0}\right)}{i_{0}}-\left.\frac{d \lambda}{d i}\right|_{i=i_{0}}}{\frac{\lambda\left(i_{0}\right)}{i_{0}}}
$$

As shown in (3), $K_{\text {sat }}$ is also a function of the current. The linear part will be discussed later after modeling.

\section{Mathematic Model of PMSM}

\section{A. PMSM Model in Stationary Reference Frame}

In order to compare easily with the rotor $d$-q reference frame, the two-phase orthogonal $\alpha-\beta$ stationary reference frame is used to express the machine electrical model instead of $a-b-c$ frame.

Equivalent current vectors, $i_{t}^{*}$ and $i_{f}^{*}$ are defined, which produce the total flux linkage and the rotor flux linkage. $i_{f}^{*}$ is assumed to be independent of the stator current and only produce the equivalent permanent magnet flux linkage. The saturation effect is modeled only from $i_{t}{ }_{t}$. As shown in Fig. $1, i_{t}{ }_{t}$ is not equal to $i_{t}$, which is a combination of the stator and rotor currents, because of the structural and saturation saliencies. The angles between the vectors in Fig. 1 are defined as

$$
\left\{\begin{array}{l}
\theta=\left(\vec{\alpha}, i_{f}^{*}\right) \\
\zeta=\left(i_{f}^{*}, i_{t}^{*}\right) \\
\rho=\left(i_{f}^{*}, i_{s}\right)
\end{array}\right.
$$

where $i_{s}$ is the input stator current vector.

The flux in the air-gap can be treated as a sinusoidal distribution for most PMSMs. Therefore the flux linkages on different vector directions are defined as the projection from the total flux linkage or called the equivalent flux linkage. In Fig.1, $\Phi^{*}{ }_{t}$ is defined as the projection of the flux vector on the total stator current direction. For the stationary reference frame, the voltage equations of PMSM machine can be described as

$$
\left\{\begin{array}{l}
v_{\alpha}=R i_{\alpha}+\frac{d}{d t} \lambda_{\alpha}^{*} \\
v_{\beta}=R i_{\beta}+\frac{d}{d t} \lambda_{\beta}^{*}
\end{array}\right.
$$

where $v_{\alpha}, v_{\beta}, i_{\alpha}$, and $i_{\beta}$ are the stator voltages and currents in the $\alpha-\beta$ stationary reference frame, $R$ is the stator resistance, and $\lambda^{*}$, $\lambda_{\beta}^{*}$ are the projected flux linkages on the $\alpha$ - and $\beta$-axes, and can be expressed as

$$
\left\{\begin{array}{l}
\lambda_{\alpha}^{*}=\lambda_{t} \cos (\zeta+\theta) \\
\lambda_{\beta}^{*}=\lambda_{t} \sin (\zeta+\theta)
\end{array}\right.
$$

where $\lambda_{t}$ is the total flux linkage in the air-gap induced by the total current vector $i_{t}{ }^{*}$.

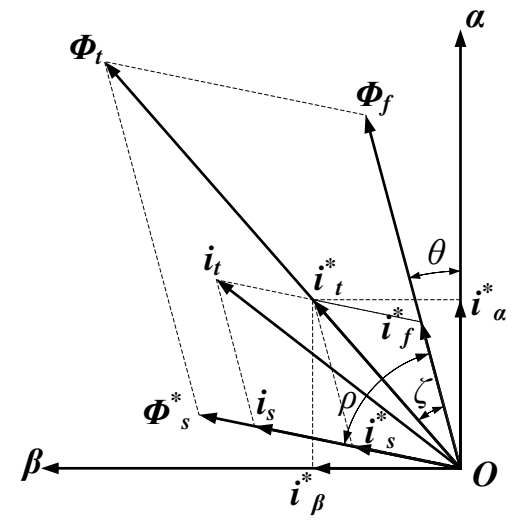

Fig. 1. Phasor diagram in $\alpha-\beta$ stationary reference frame

After decoupling all the current vectors onto orthogonal $\alpha-\beta$ axes, the equivalent total current is composed of the rotor and stator currents with the structural saliency factors and can be expressed as

$$
\begin{aligned}
i_{t}^{*} & =\sqrt{\left(i_{\alpha}^{*}\right)^{2}+\left(i_{\beta}^{*}\right)^{2}} \\
& =\sqrt{\left[K_{\alpha}\left(i_{\alpha}+i_{f}^{*} \cos \theta\right)\right]^{2}+\left[K_{\beta}\left(i_{\beta}+i_{f}^{*} \sin \theta\right)\right]^{2}}
\end{aligned}
$$

where $K_{\alpha}$, and $K_{\beta}$ are the structural saliency factors of the $\alpha$ - and $\beta$-axis with the assumption that the linear inductance follows a spatially sinusoidal distribution. The contributions to the total flux linkage are projected to the axes as linear vectors and these factors depend on the structural saliency. They could be expressed as

$$
\left\{\begin{array}{l}
K_{\alpha}=\frac{1+K_{s t r} \cos 2 \theta}{1+K_{s t r} \cos 2 \rho} \\
K_{\beta}=\frac{1-K_{s t r} \cos 2 \theta}{1+K_{s t r} \cos 2 \rho}
\end{array}\right.
$$


It can be found out that the flux linkages on $\alpha$ - and $\beta$-axis are compound functions of the rotor current, stator current and rotor position, so one has

$$
\frac{d \lambda_{\alpha}^{*}}{d t}=\frac{\partial \lambda_{\alpha}^{*}}{\partial i_{\alpha}} \cdot \frac{d i_{\alpha}}{d t}+\frac{\partial \lambda_{\alpha}^{*}}{\partial i_{\beta}} \cdot \frac{d i_{\beta}}{d t}+\frac{\partial \lambda_{\alpha}^{*}}{\partial i_{f}^{*}} \cdot \frac{d i_{f}^{*}}{d t}+\frac{\partial \lambda_{\alpha}^{*}}{\partial \theta} \cdot \frac{d \theta}{d t}
$$

For a PMSM machine, because the magnitude of the rotor flux linkage is constant, the corresponding equivalent rotor current is also constant and we have

$$
\frac{d i_{f}^{*}}{d t}=0
$$

The last term in (9) is defined as the back-emf of the phase winding, $e_{\alpha}$. Substituting (6), (7), (8) and (10) into (9), one obtains

$$
\begin{aligned}
& \frac{d \lambda_{\alpha}^{*}}{d t}=\left[\frac{d \lambda_{t}^{*}}{d i_{t}^{*}} K_{\alpha} \cos ^{2}(\zeta+\theta)+\frac{\lambda_{t}^{*}}{i_{t}^{*}} K_{\alpha} \sin ^{2}(\zeta+\theta)\right] \cdot \frac{d i_{\alpha}}{d t} \\
& +\left[\frac{d \lambda_{t}^{*}}{d i_{t}^{*}} K_{\beta} \sin (\zeta+\theta) \cos (\zeta+\theta)-\frac{\lambda_{t}^{*}}{i_{t}^{*}} K_{\beta} \sin (\zeta+\theta) \cos (\zeta+\theta)\right] \\
& \cdot \frac{d i_{\beta}}{d t}+e_{\alpha}
\end{aligned}
$$

As mentioned above, $d \lambda_{t}^{*} / d i_{t}^{*}$ and $\lambda_{t}^{*} / i_{t}^{*}$ are not equal in the nonlinear machine model due to the saturation effect. The linear inductance $\lambda_{t}^{*} / i_{t}^{*}$ is then defined as $L_{t}\left(i_{t}^{*}\right)$ and expressed as

$$
\left\{\begin{array}{l}
\frac{\lambda_{t}^{*}}{i_{t}^{*}}=L_{t}\left(i_{t}^{*}\right) \\
\frac{d \lambda_{t}^{*}}{d i_{t}^{*}}=\left[1-K_{\text {sat }}\left(i_{t}^{*}\right)\right] L_{t}\left(i_{t}^{*}\right)
\end{array}\right.
$$

Therefore, the machine voltage equation (5) can be rewritten as

$$
\left[\begin{array}{c}
v_{\alpha} \\
v_{\beta}
\end{array}\right]=R\left[\begin{array}{l}
i_{\alpha} \\
i_{\beta}
\end{array}\right]+\left[\begin{array}{ll}
L_{\alpha \alpha} & L_{\alpha \beta} \\
L_{\beta \alpha} & L_{\beta \beta}
\end{array}\right] \frac{d}{d t}\left[\begin{array}{c}
i_{\alpha} \\
i_{\beta}
\end{array}\right]+\left[\begin{array}{c}
e_{\alpha} \\
e_{\beta}
\end{array}\right]
$$

where the nonlinear inductance matrix can be expressed as

$$
\begin{aligned}
& {\left[\begin{array}{ll}
L_{\alpha \alpha} & L_{\alpha \beta} \\
L_{\beta \alpha} & L_{\beta \beta}
\end{array}\right]} \\
& =\left[\begin{array}{cc}
L_{t} K_{\alpha}\left(1-K_{s a t} \cos ^{2}(\zeta+\theta)\right) & -\frac{1}{2} L_{t} K_{\beta} K_{s a t} \sin 2(\zeta+\theta) \\
-\frac{1}{2} L_{t} K_{\alpha} K_{\text {sat }} \sin 2(\zeta+\theta) & L_{t} K_{\beta}\left(1-K_{\text {sat }} \sin ^{2}(\zeta+\theta)\right)
\end{array}\right]
\end{aligned}
$$

\section{B. PMSM Model in Rotor Reference Frame}

Rotating orthogonal $d-q$ axis is a widely used rotor field oriented reference frame, where the stator side variables could be converted into rotor side rotating with the rotor field. The projected current and voltage vectors are relatively motionless to the rotor flux. The Park-Clarke transform can also be applied to the nonlinear machine model because the flux vectors are all obtained from the total flux linkage projection. Then the voltage equation

$$
\left[\begin{array}{c}
v_{d} \\
v_{q}
\end{array}\right]=R\left[\begin{array}{l}
i_{d} \\
i_{q}
\end{array}\right]+\frac{d}{d t}\left[\begin{array}{l}
\lambda_{d}^{*} \\
\lambda_{q}^{*}
\end{array}\right]+\left[\begin{array}{c}
-\lambda_{q}^{*} \\
\lambda_{d}^{*}
\end{array}\right] \omega_{e}
$$

is valid for nonlinear modeling, where $\lambda^{*}$ and $\lambda^{*}$ are the equivalent flux linkages on the $d$ - and $q$-axes which are projected from the total flux linkage.

The phasor diagram in the $d$ - $q$ reference frame is shown in Fig. 2 and the angles between the vectors are defined same as those in (4).

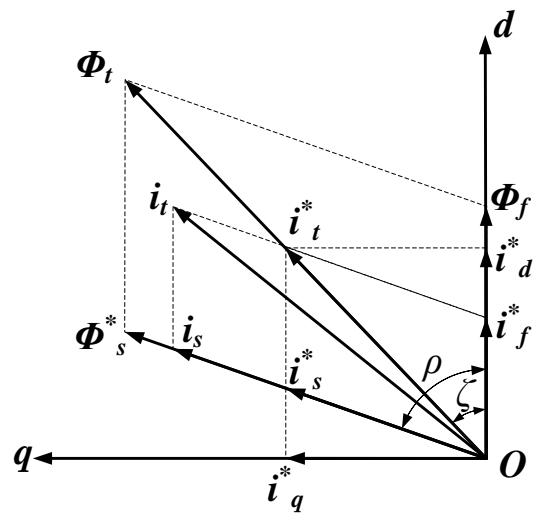

Fig. 2. Phasor diagram in $d$-q rotor reference frame

The flux linkages in (15) can be expressed by the total flux linkage and the angle as below

$$
\left\{\begin{array}{l}
\lambda_{d}^{*}=\lambda_{t}^{*} \cos \zeta \\
\lambda_{q}^{*}=\lambda_{t}^{*} \sin \zeta
\end{array}\right.
$$

The structural saliency factors of the $d$ - and $q$-axes are defined as

$$
\left\{\begin{array}{l}
K_{d}=\frac{1+K_{s t r}}{1+K_{s t r} \cos 2 \rho} \\
K_{q}=\frac{1-K_{s t r}}{1+K_{s t r} \cos 2 \rho}
\end{array}\right.
$$

Based on the same definition of the linear inductance as in (12), the PMSM voltage equation in the rotor reference frame can be rewritten as 


$$
\left[\begin{array}{c}
v_{d} \\
v_{q}
\end{array}\right]=R\left[\begin{array}{c}
i_{d} \\
i_{q}
\end{array}\right]+\left[\begin{array}{ll}
L_{d d} & L_{d q} \\
L_{q d} & L_{q q}
\end{array}\right] \frac{d}{d t}\left[\begin{array}{c}
i_{d} \\
i_{q}
\end{array}\right]+\left[\begin{array}{c}
-\lambda_{q}^{*} \\
\lambda_{d}^{*}
\end{array}\right] \omega_{e}
$$

where the nonlinear inductance matrix can be expressed as

$$
\left[\begin{array}{ll}
L_{d d} & L_{d q} \\
L_{q d} & L_{q q}
\end{array}\right]=\left[\begin{array}{cc}
L_{t} K_{d}\left(1-K_{s a t} \cos ^{2} \zeta\right) & -\frac{1}{2} L_{t} K_{q} K_{s a t} \sin 2 \zeta \\
-\frac{1}{2} L_{t} K_{d} K_{s a t} \sin 2 \zeta & L_{t} K_{q}\left(1-K_{s a t} \sin ^{2} \zeta\right)
\end{array}\right]
$$

From (18) and (19), the traditional PMSM linear model can be obtained as an ideal condition, where the saturation saliency is ignored, $K_{\text {sa }}=0$, as shown below

$$
\left[\begin{array}{l}
v_{d} \\
v_{q}
\end{array}\right]=R\left[\begin{array}{l}
i_{d} \\
i_{q}
\end{array}\right]+\left[\begin{array}{cc}
L_{d} & 0 \\
0 & L_{q}
\end{array}\right] \frac{d}{d t}\left[\begin{array}{c}
i_{d} \\
i_{q}
\end{array}\right]+\left[\begin{array}{c}
-\lambda_{q} \\
\lambda_{d}
\end{array}\right] \omega_{e}
$$

\section{Linear Inductance Component}

The linear inductance component defined in (12) is still a function of the stator current and the rotor position. Based on the magnetization curve, the linear inductance $\lambda_{t}^{*} / i_{t}^{*}$ variation is always smaller than that of the differential inductance $d \lambda_{t}^{*} / d i_{t}^{*}$ and could be neglected. Then the linear inductance component is assumed to be fixed and expressed by using the given $L_{d}$ and $L_{q}$ values, which are always known for the machine. The machine inductance matrixes in (14) and (19) could be rewritten as

$$
\begin{aligned}
& {\left[\begin{array}{ll}
L_{\alpha \alpha} & L_{\alpha \beta} \\
L_{\beta \alpha} & L_{\beta \beta}
\end{array}\right]=\left[\begin{array}{l}
L_{a v}\left(1+K_{s t r} \cos 2 \theta\right)\left(1-K_{s a t} \cos ^{2}(\zeta+\theta)\right) \\
-\frac{1}{2} L_{a v}\left(1+K_{s t r} \cos 2 \theta\right) K_{s a t} \sin 2(\zeta+\theta)
\end{array}\right.} \\
& \left.\begin{array}{r}
-\frac{1}{2} L_{a v v}\left(1-K_{s t r} \cos 2 \theta\right) K_{s a t} \sin 2(\zeta+\theta) \\
L_{a v}\left(1-K_{s t r} \cos 2 \theta\right)\left(1-K_{s a t} \sin ^{2}(\zeta+\theta)\right)
\end{array}\right]
\end{aligned}
$$

where $L_{a v}=\left(L_{d}+L_{q}\right) / 2$ is the average linear inductance in the $d$ and $q$-axes expressed as

$$
\left[\begin{array}{ll}
L_{d d} & L_{d q} \\
L_{q d} & L_{q q}
\end{array}\right]=\left[\begin{array}{cc}
L_{d}\left(1-K_{s a t} \cos ^{2} \zeta\right) & -\frac{1}{2} L_{q} K_{s a t} \sin 2 \zeta \\
-\frac{1}{2} L_{d} K_{s a t} \sin 2 \zeta & L_{q}\left(1-K_{s a t} \sin ^{2} \zeta\right)
\end{array}\right]
$$

\section{EXPERIMENT OF INDUCTANCE TEST}

In the proposed PMSM model, several parameters in the machine model are required to express the inductance matrix. In order to test and verify the nonlinear machine model, an inductance test was carried out on an SPMSM and the numerical inductance model is regressed based on the test data [33].

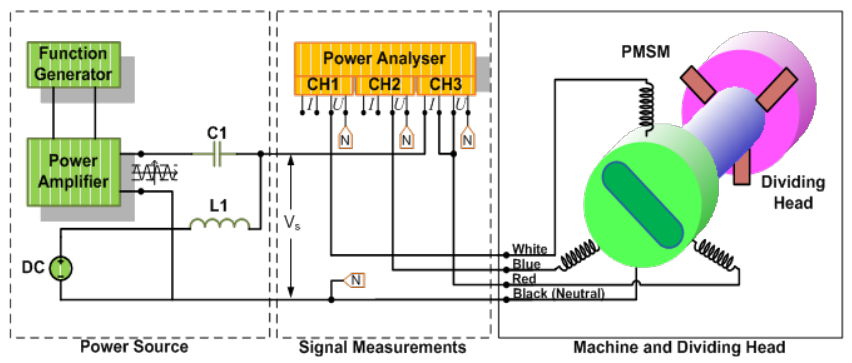

Fig. 3. Experiment platform for incremental inductance test

Fig. 3 shows the block diagram of the experiment set up. During the test, the stator currents are fixed at several different levels from 0 to $6 \mathrm{~A}$ at which the magnetic circuit is fully saturated. For each current offset, by applying a small AC current component the incremental inductance of a particular rotor position is measured. The magnitude of the injected voltage is limited as $0.2 \mathrm{~V}$. Therefore, the collected incremental inductance values are supposed to be accurate enough to plot the inductance curve. By changing the rotor position with a dividing head, a series of inductance is recorded with a resolution of 6 electrical degrees.

A function of both the current and rotor position is defined to express the inductance [33] as

$$
L(i, \theta)=I(i) \cdot A \cdot C(\theta)
$$

where $I(i)=\left[\begin{array}{lllll}1 & i^{1} & i^{2} & \cdots & i^{m}\end{array}\right]$;

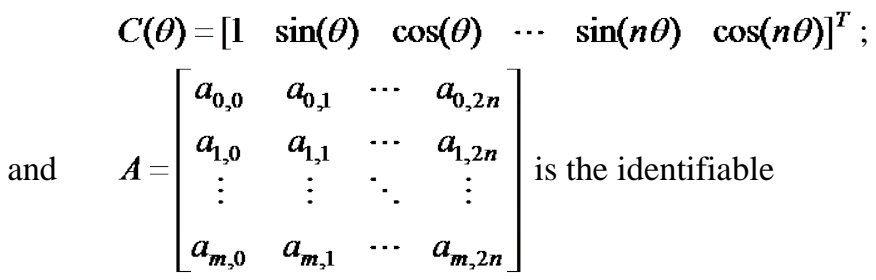
parameter matrix.

Fig. 4 shows the inductance curves collected at different current offset levels. It can be found that the inductances are periodical fluctuant functions. To obtain better regression results, the Least Relative Residual Sum of Square (LRRSS) method is employed. For the objective function $L(i, \theta)$, the relative residual sum of square is defined as

$$
E_{r e}(A)=\sum_{i=0}^{6} \sum_{\theta=0}^{2 \pi}\left[\frac{I(i) \cdot A \cdot C(\theta)-L_{\text {test }}(i, \theta)}{L_{\text {test }}(i, \theta)}\right]^{2}
$$

where $L_{\text {test }}(i, \theta)$ is the test inductance value. 


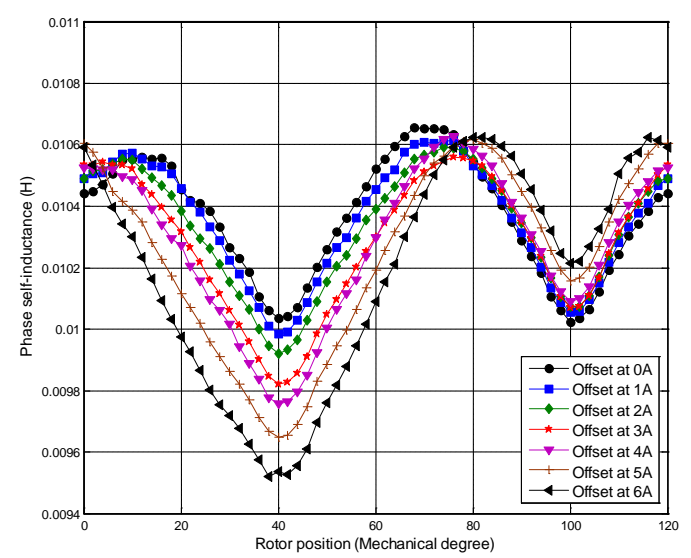

Fig. 4. Measured incremental self-inductance curves at different current offset levels

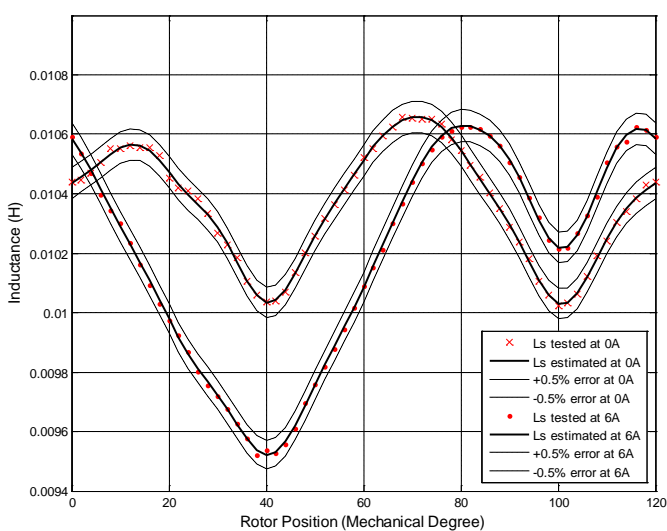

Fig. 5. Measured and estimated incremental self-inductance at different current offsets

Fig. 5 shows the comparison between the tested and regressed self-inductance of phase A at current offsets from $0 \mathrm{~A}$ to $6 \mathrm{~A}$, where $\pm 0.5 \%$ error bands are added. It can be found that the relative errors of the inductances are very small and the regressed objective function can be used to describe the variable self-inductance. The same regression method is applied to the mutual-inductance coefficients identification. Fig. 6 shows the comparison between the tested and regressed mutual-inductance between phases A and B at different current offsets.

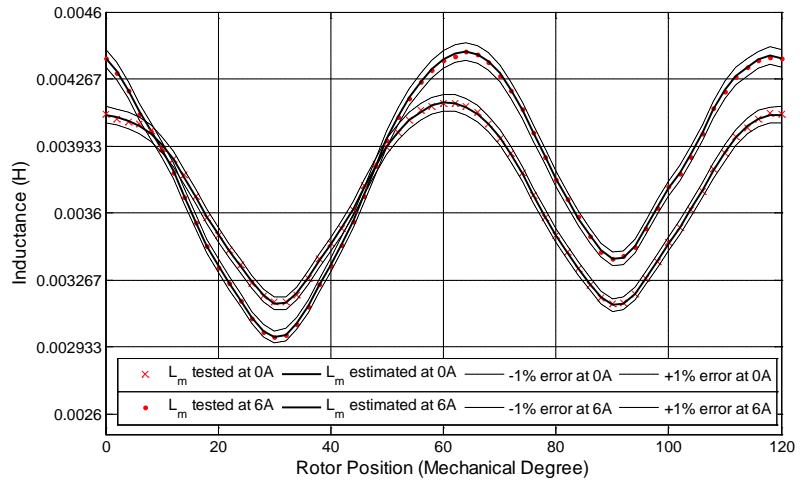

Fig. 6. Measured and estimated incremental mutual-inductance at different current offsets
Therefore, a nonlinear inductance model is built up for this three-phase machine. An accurate inductance matrix can be calculated for given stator currents and rotor position. This model incorporates both the machine structural and the saturation saliencies for the test machine.

\section{MODEL VeRIFICATION}

\section{A. Tested $K_{\text {str }}$ and $K_{\text {sat }}$}

The tested SPMSM has a small structural saliency, but a reasonably large saturation saliency. The stator current vector is set in the same direction of the rotor current, and the equivalent total current is also in this direction and the angles $\zeta=0, \rho=0$. Then the inductance matrix in $d-q$ reference frame could be simplified as

$$
\left[\begin{array}{ll}
L_{d d} & L_{d q} \\
L_{q d} & L_{q q}
\end{array}\right]=\left[\begin{array}{cc}
L_{d}\left(1-K_{s a t}\right) & 0 \\
0 & L_{q}
\end{array}\right]
$$

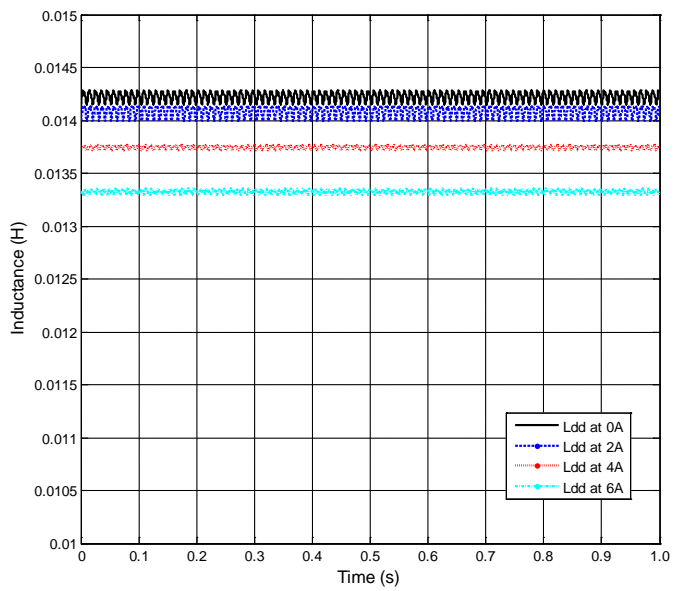

(a) $L_{d d}$ varying against stator current

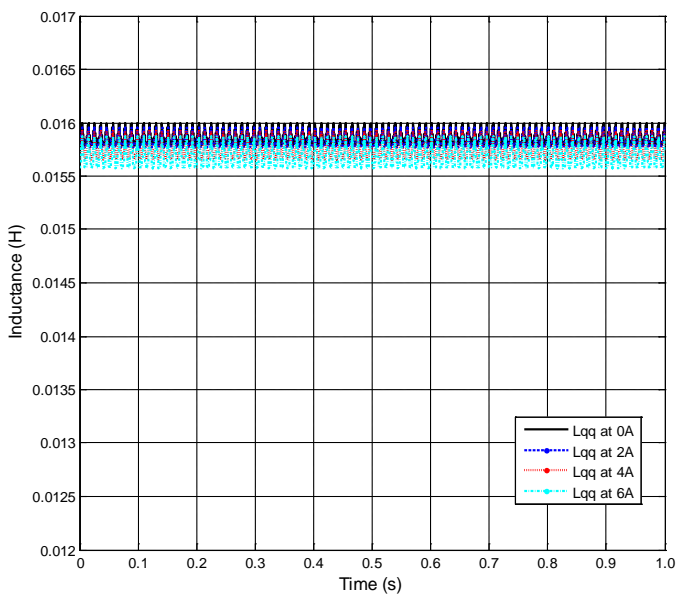

(b) $L_{q q}$ varying against stator current

Fig. 7. $d$ - and $q$-inductance varying against stator current level

In order to identify $K_{\text {str }}$ and $K_{\text {sat }}$, the three-phase inductance matrix collected from the test machine is transferred into the $d-q$ reference frame at different stator current levels. The $d$ - and 
$q$-axis inductance is supposed to be constant and the measured inductance profiles are shown in Fig. 7. It can be found the inductance curves show good agreement with (25), where the $q$-axis inductance is almost constant and the $d$-axis inductance varies against the stator current due to the saturation effect.

When the input stator current offset is set to zero, the equivalent total current can be assumed that only formed from the rotor equivalent current and the $K_{\text {sat }}$ here is zero. Then the linear inductances are read out and the $K_{\text {str }}$ is calculated for the test machine as shown below

$$
\left\{\begin{array}{l}
L_{d}=0.0142 H \\
L_{q}=0.0159 H \\
L_{a v}=0.0151 H \\
K_{s t r}=-5.65 \%
\end{array}\right.
$$

For a given machine, $K_{\text {str }}$ is fixed and would not change with other variables, such as the rotor position or stator current. In the following analysis, $K_{\text {str }}$ of the tested machine is fixed and the values in (26) are also used as the linear inductances.

On the other hand, $K_{\text {sat }}$ always depends on the nonlinear magnetization curve of the material and cannot be analytically expressed. As shown in (25), the $d$-axis inductance is a function of $K_{\text {sat }}$ for different current levels. Several tests have been carried out to check the $K_{\text {sat }}$ as shown in Fig. 7(a). The relationship between the current magnitude and the $K_{\text {sat }}$ is shown in Table I.

TABLE I

RELATIONSHIP BETWEEN CURRENT AND $K_{S A T}$ $\left(\lambda_{f}=0.1495 \mathrm{~Wb}, \zeta=0, P=0, K_{s t r}=-5.65 \%\right)$

\begin{tabular}{ccc}
\hline \hline $\begin{array}{c}\text { Current Offset } \\
i_{s}(\mathrm{~A})\end{array}$ & $\begin{array}{c}\text { Average d-inductance } \\
L_{d d}(\mathrm{mH})\end{array}$ & $K_{\text {sat }}(\%)$ \\
\hline 0 & 14.23 & 0 \\
1 & 14.14 & 0.60 \\
2 & 14.08 & 1.02 \\
3 & 13.91 & 2.23 \\
4 & 13.74 & 3.39 \\
5 & 13.57 & 4.59 \\
6 & 13.33 & 6.33 \\
\hline \hline
\end{tabular}

At the same time, the measured mutual inductances between the $d$ - and $q$-axes are all smaller than $0.03 \mathrm{mH}$, which can be ignored and comparable with zero shown in (25).

\section{B. Inductance Calculation}

After obtaining $K_{\text {str }}$ and $K_{\text {sat }}$, the inductances in the stator reference frame are calculated and compared with the tested data. The linear inductance and $K_{\text {str }}$ are shown in (26). Then the inductance matrix in stationary frame can be rewritten as a function of $K_{\text {sat }}$, which can be determined by the current value based on the look up table shown in Table I.

First of all, the stator current vector is set on the same direction of the rotor current, $\zeta=0, \rho=0$. Taken as an example, the self-inductance on $\beta$-axis can be expressed as

$$
L_{\beta \beta}=0.0151(1+0.0565 \cos 2 \theta)\left(1-K_{\text {sat }} \sin ^{2} \theta\right)
$$

In Fig. 8, the calculated inductance curves are estimated based on (27) and compared with the measured inductance curves, which come from the inductance test and the regressed nonlinear model.

Several different stator current levels are applied to calculate the self-inductance curves. It can be found out that $L_{\beta \beta}$ varies against the stator current value. The calculated curves in Fig. 8 are close to the tested inductance curves.

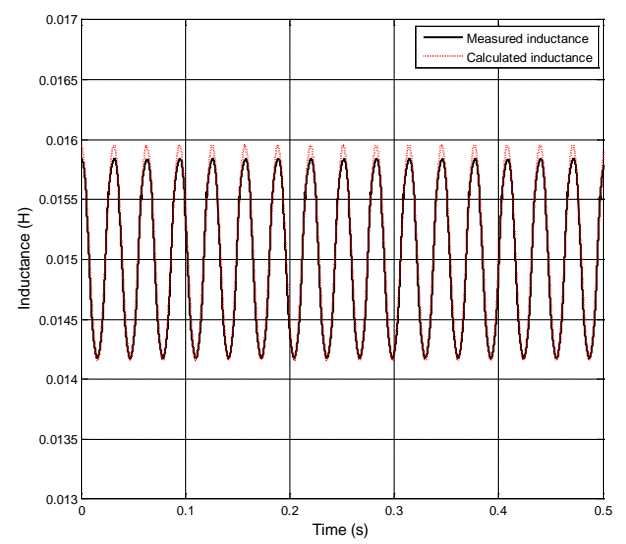

(a) Stator current $=1 \mathrm{~A}, K_{\text {str }}=0.60 \%$

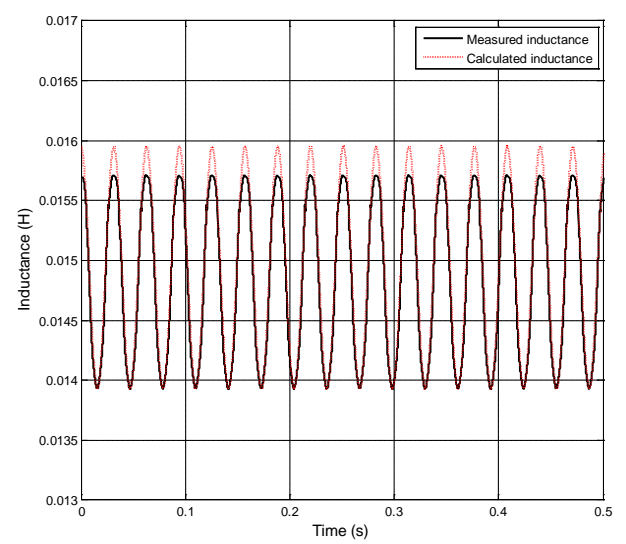

(b) Stator current $=3 \mathrm{~A}, K_{\text {str }}=2.23 \%$

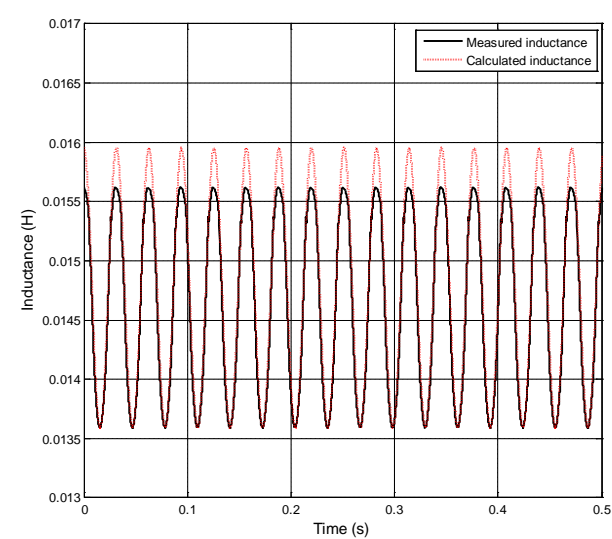

(c) Stator current=5A, $K_{\text {str }}=4.59 \%$

Fig. 8. Self-inductance comparison between the measured and calculated values $\left(\zeta=0, \rho=0, K_{\text {str }}=-5.65 \%\right)$ 


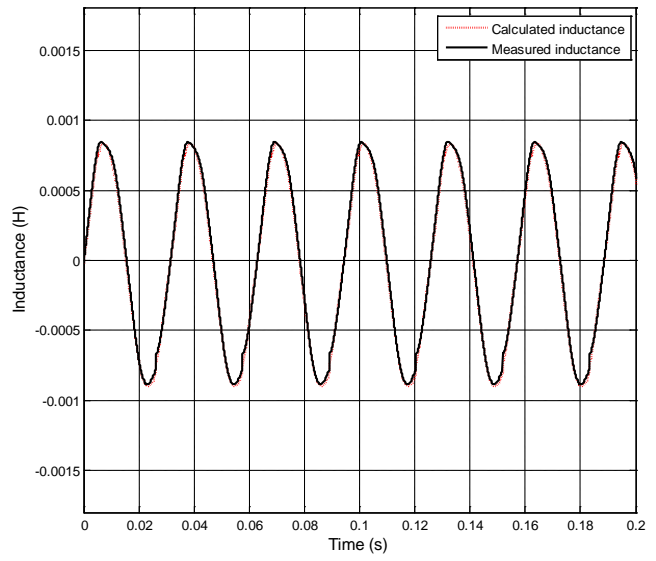

(a) Stator current $=1 \mathrm{~A}, K_{\text {str }}=0.60 \%$

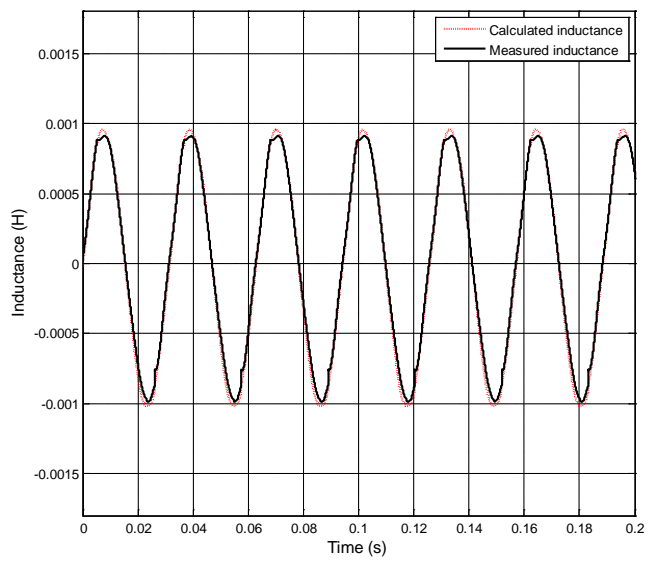

(b) Stator current=3A, $K_{\text {str }}=2.23 \%$

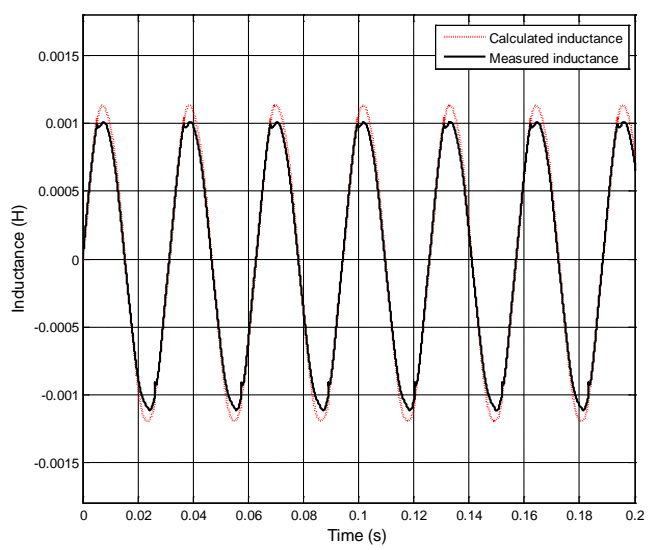

(c) Stator current $=5 \mathrm{~A}, K_{\text {str }}=4.59 \%$

Fig. 9. Mutual-inductance comparison between the measured and calculated values ( $\zeta=0, \rho=0, K_{\text {str }}=-5.65 \%$ )

On the other hand, the mutual-inductance between the orthogonal axes is non-zero as shown in (21). It is related to the $K_{\text {sat }}$ and would be zero when there is no saturation or no current, so the measured mutual inductance at $0 \mathrm{~A}$ is marked as error signal and in Fig. 9 the calculated inductance is plotted as

$$
L_{\alpha \beta}=-0.00755(1+0.0565 \cos 2 \theta) K_{\text {sat }} \sin 2 \theta+L_{\alpha \beta_{-} e r r}
$$

where $L_{\alpha \beta_{\_} \text {err }}$ is the measured signal when the current offset is zero.

Then the mutual-inductance $L_{\alpha \beta}$ is calculated at different current offsets and shown in Fig. 9. The calculated curves show good agreement with the measured inductance curves.

The error between the calculated curves and the measured curves in Fig. 8 and Fig. 9 mainly exist around the maximum inductance area. It may come from the linear inductance component assumption that the magnetization curve is linear when the current is smaller than the equivalent rotor current and $L_{d}$ and $L_{q}$ are the linear part inductances. In the measured inductance model, the saturation curve is also nonlinear in this area.

When the machine is operating at steady state, the spatial stator current vector is rotating at the synchronous speed with the rotor. The magnitude of the stator current is constant. Then the angle $\zeta$ between the current vectors is always nonzero and can be calculated by

$$
\cos \zeta=\frac{K_{d}\left(i_{d}+i_{f}\right)}{\sqrt{\left[K_{d}\left(i_{d}+i_{f}\right)\right]^{2}+\left[K_{q} i_{q}\right]^{2}}}
$$

where $K_{d}, K_{q}$ defined in (17) can be obtained based on the $K_{\text {str }}$ and the stator current vector direction angle, $\rho$.

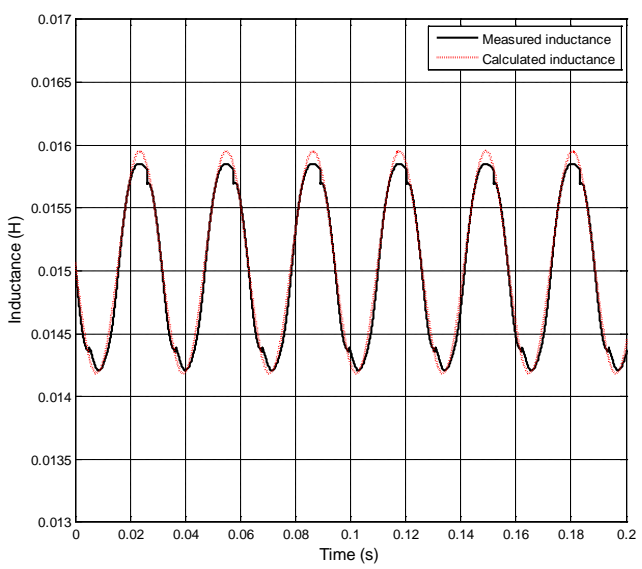

(a) Stator current $=1 \mathrm{~A}, \rho=45^{\circ}, K_{\text {str }}=0.4339 \%$

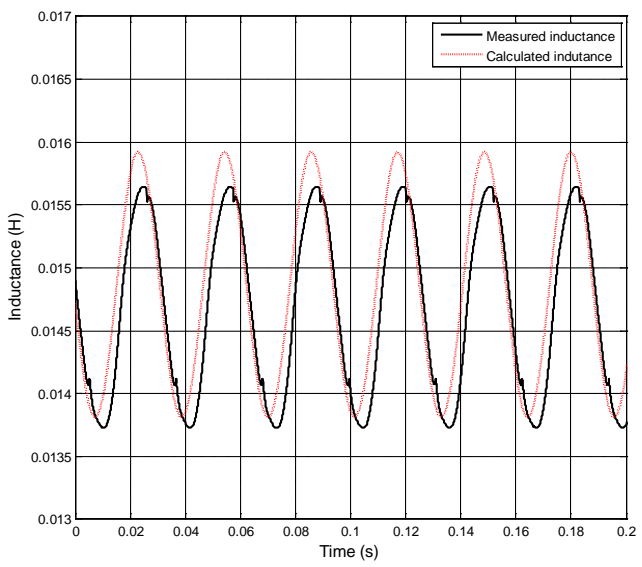

(b) Stator current $=5 \mathrm{~A}, \rho=45^{\circ}, K_{\text {str }}=3.2399 \%$

Fig. 10. Self-inductance comparison between the measured and calculated values $\left(K_{\text {str }}=-5.65 \%, \rho=45^{\circ}\right)$ 


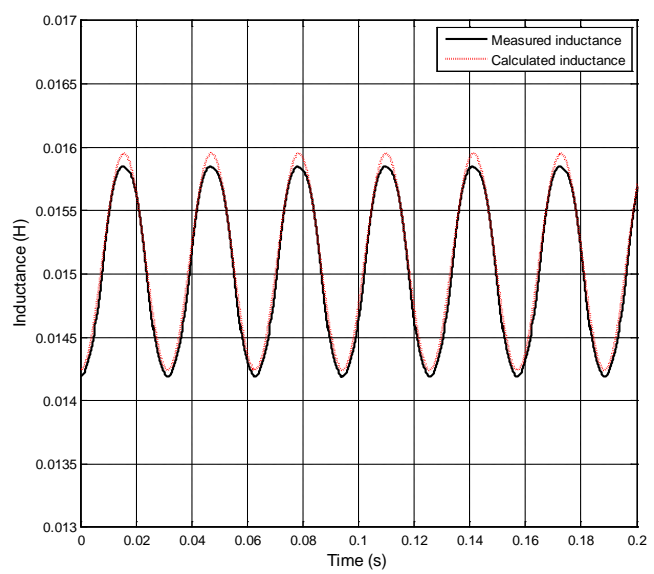

(a) Stator current $=1 \mathrm{~A}, \rho=90^{\circ}, K_{\mathrm{str}}=0.02 \%$

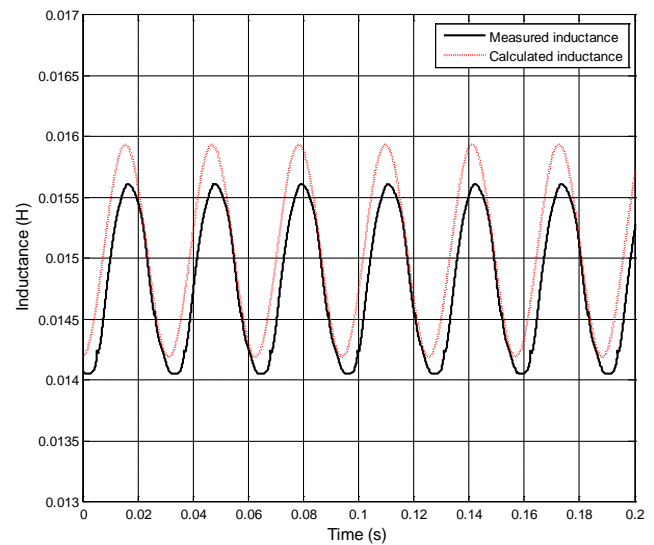

(b) Stator current $=5 \mathrm{~A}, \rho=90^{\circ}, K_{\text {str }}=0.4884 \%$

Fig. 11. Self-inductance comparison between the measured and calculated values $\left(K_{\text {str }}=-5.65 \%, \rho=90^{\circ}\right)$

The self-inductance on $\beta$-axis is expressed as

$$
L_{\beta \beta}=0.0151(1+0.0565 \cos 2 \theta)\left(1-K_{s a t} \sin ^{2}(\zeta+\theta)\right)
$$

where $K_{\text {sat }}$ given in Table I is indexed by using the calculated total current values.

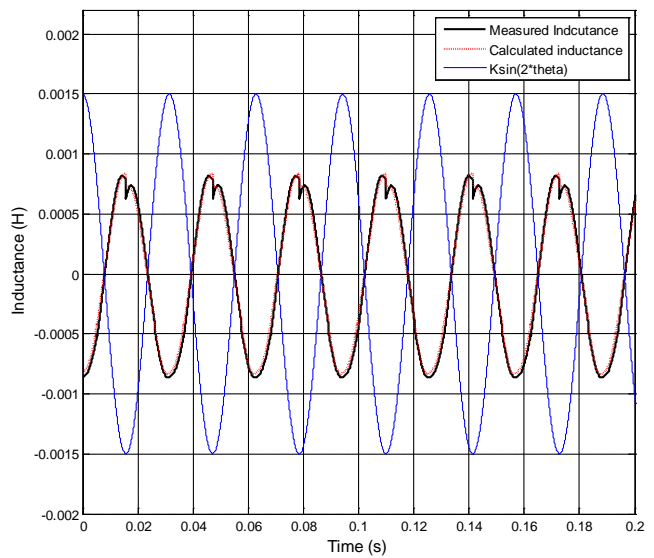

(a) Stator current $=1 \mathrm{~A}, \rho=45^{\circ}, K_{\text {str }}=0.4339 \%$

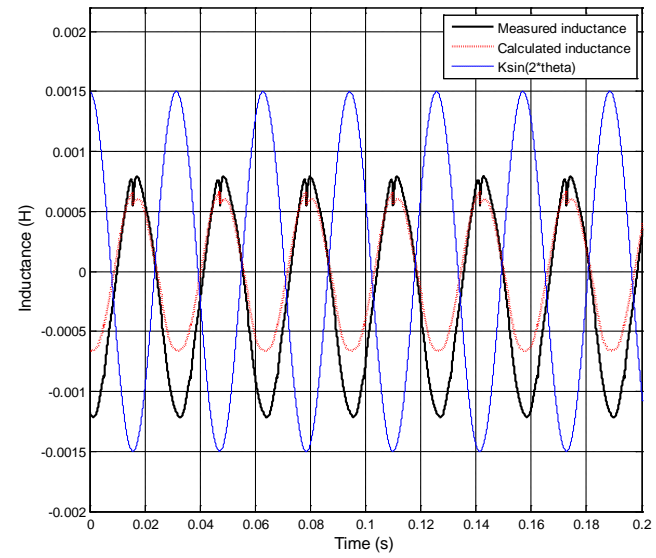

(b) Stator current $=5 \mathrm{~A}, \rho=45^{\circ}, K_{\text {str }}=3.2399 \%$

Fig. 12. Mutual-inductance comparison between the measured and calculated values $\left(K_{\text {str }}=-5.65 \%, \rho=45^{\circ}\right)$

The self-inductance on $\beta$-axis, $L_{\beta \beta}$ is calculated and compared with the measured values at different $\rho$ values as shown in Fig. 10 and Fig. 11.

The same calculation method is applied to the mutual inductance as well. Fig. 12 shows the calculated and measured mutual-inductance curves, where a sinusoidal curve $K \sin (2 \theta)$ is added to indicate the mutual inductance phase.

\section{Error Discussion}

As shown above, comparisons are carried out between the estimated and measured inductance values, where errors could be found out between the curves.

The main error comes from the inaccurate machine parameters. The PMSM mathematic model built up in this paper is for all the PMSMs, including IPMSM and SPMSM, which incorporates both the structural and saturation saliencies. However, the parameters in the model, such as $K_{\text {str }}$, linear inductance value and the saturation curve, are unknown for the test machine. Some of these parameters are identified from the measured values and some parts are simplified by mainly two assumptions: (1) the magnetization curve is linear when the total current is smaller than the rotor equivalent current value; and (2) the saturation curve is simplified as a look up table and all the sections between the points are linear.

Therefore, the error signal could be found out in the comparisons. Especially when the stator current magnitude is big, the error is large because of the inaccurate $K_{\text {sat }}$ and the current composition angle values.

However, if the design parameters are known, an accurate machine model can be developed. $K_{\text {str }}$ could be calculated by using the accurate $L_{d}$ and $L_{q}$, and the linear inductance can also be found out. $K_{\text {sat }}$ could be updated by using the more accurate magnetization curve.

Additionally, the original inductance data are collected from an SPMSM by using incremental inductance method. There are reading errors on the dividing head, which controls the rotor position angle in the test, and also on the power analyzer, which measures the voltage, current and power on the machine phase. The phase winding resistance varies with the temperature, 
especially at a high current offset, and the measured inductance will be influenced. After taking all the inductance values, the nonlinear inductance function is regressed by using the LRSS method, which aims to minimize the residual sum of square but not regress it to zero. So there is small residual error in the nonlinear inductance model.

\section{EXPERIMENT VERIFICATION}

A simulation SPMSM machine block is built up in MATLAB/SIMULINK based on the proposed mathematical model. The performance of the simulation model is compared with the experiment result. The open loop characteristics of the machine are recorded. Fig. 13 shows the simulated no-load speed and torque of the machine.

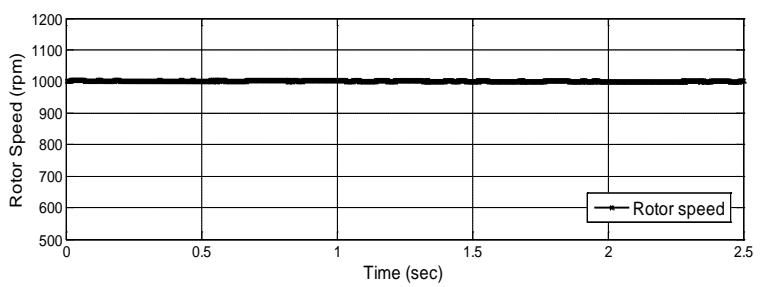

(a) No-load speed performance

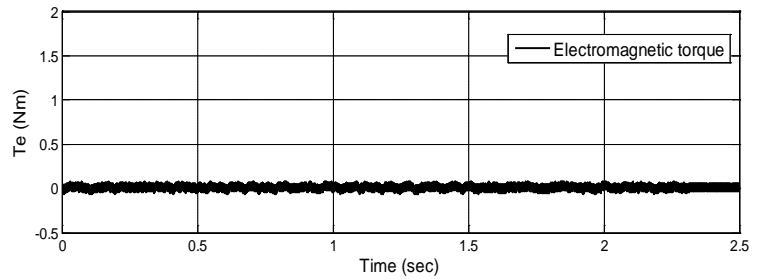

(b) No-load electromagnetic torque performance

Fig. 13. Simulated open-loop machine performance based on the proposed mathematic model without load

The experiment platform setup is shown in Fig. 14. The SPMSM is coupled with a dynamometer via the torque transducer, which could display the accurate mechanical torque and speed on the shaft. Table II shows the parameters of the machine. The MAGTROL hysteresis dynamometer is controlled by the DSP6000 series controller and can produce constant or variable load torque. The SPMSM drive algorithm is implemented by using dSPACE/ControlDesk. Table III shows the information of the equipments. For the no-load test, Fig. 15 shows the measured no-load speed performance of the system, which is measured by using the M-TEST software.

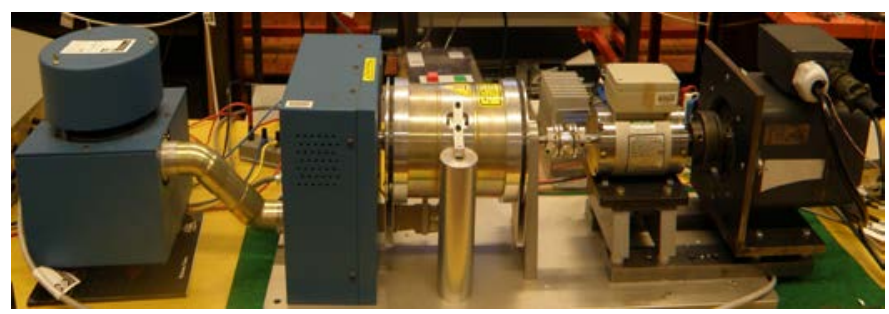

Fig. 14. Experiment platform setup including machine, torque transducer and dynamometer
TABLE II

PARAMETERS OF TESTED SPMSM

\begin{tabular}{cc}
\hline \hline Parameters & Values \\
\hline Number of Poles & 6 \\
Rated Power & $1000 \mathrm{~W}$ \\
Rated Current & $6.5 \mathrm{~A}$ \\
Rated Speed & $2000 \mathrm{rev} / \mathrm{min}$ \\
Rated Torque & $4.8 \mathrm{Nm}$ \\
\hline \hline
\end{tabular}

TABLE III

EQUIPMENTS INFORMATION OF THE EXPERIMENT SYSTEM

\begin{tabular}{cc}
\hline \hline Equipment & Model/Version \\
\hline SPMSM & LanZhou 6071-6AC21-2-Z \\
Dynamometer & MAGTROL HD-715-8N \\
Dynamometer controller & MAGTROL DSP6000 \\
M-TEST software & V5.0 (Rev 8.6.1) \\
Torque transducer & MCRT $^{\circledR}$ 79001V-(2-2)-NFZ-15000 \\
dSPACE & DS1104 \\
ControlDesk & V2.8 Unicode \\
\hline \hline
\end{tabular}

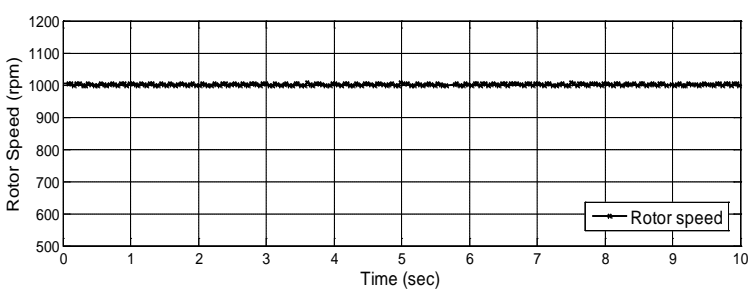

Fig. 15. Experimental open-loop machine performance without load

Then a constant load torque is applied to the rotor shaft. Fig. 16 shows the simulated speed, torque, and phase current curves based on the proposed mathematic model. The load torque is fixed at $2 \mathrm{Nm}$.

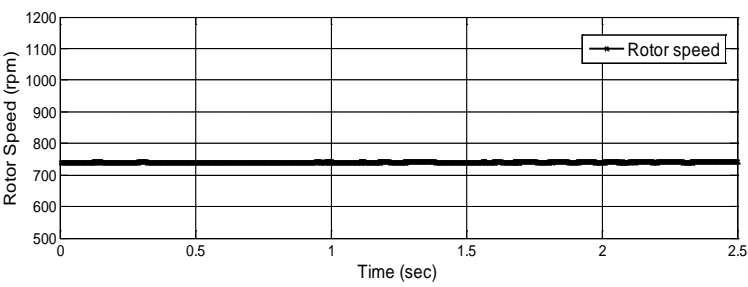

(a) Loaded speed performance

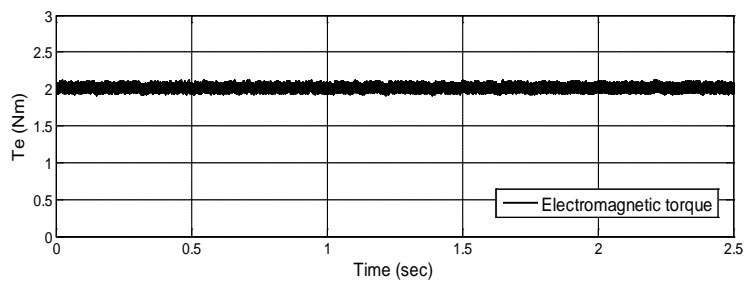

(b) Loaded electromagnetic torque performance

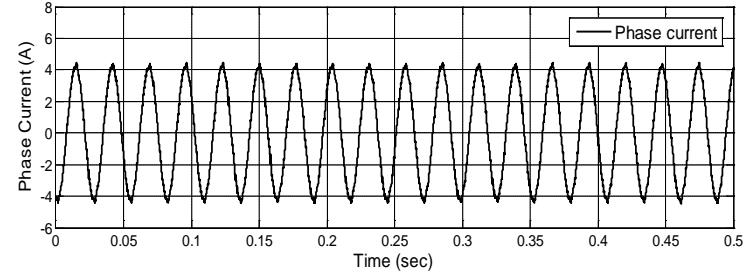

(c) Loaded phase current curve

Fig. 16. Simulated loaded machine performance based on the proposed mathematic model 
The same test is carried out on the experiment platform. A constant load torque is applied to the rotor shaft via the dynamometer. The rotor speed is recorded by M-TEST, and the phase current is recorded by ControlDesk. The performance curves are plotted as shown in Fig. 17.

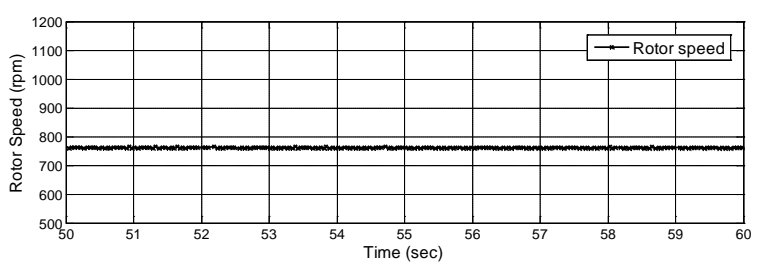

(a) Loaded speed performance

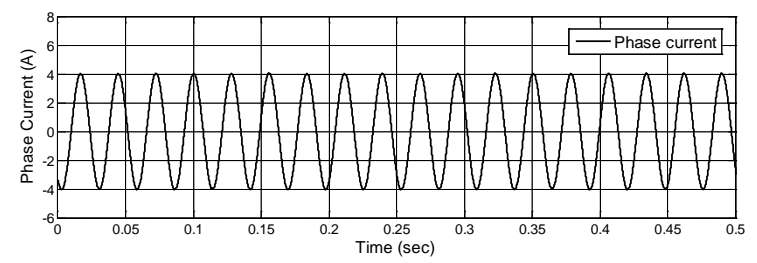

(b) Loaded phase current curve

Fig. 17. Experimental open-loop machine performance with $2 \mathrm{Nm}$ load torque

It can be found that the simulated and experimently measured curves are in good agreement. The errors of the speed and current mainly come from the friction coefficient of the model and the assumptions made in the proposed mathematic model.

\section{CONCLUSION}

This paper proposes a comprehensive mathematic model for PMSMs, in which the structural and saturation saliencies are decoupled and indicated by using $K_{\text {str }}$ and $K_{\text {sat }}$. The inductance matrix of the model has been carried out and expressed in both stationary and rotor reference frames.

Based on inductance test, a numerical inductance model was built up for an SPMSM, in which the inductance was modeled as a function of the stator current and rotor position. According to the measured data, $K_{\text {str }}$ and $K_{\text {sat }}$ of the test machine were estimated and input to the machine model.

The estimated inductance curves were compared with the measured inductances. The inductance profiles showed good agreement and the error analysis was carried out. This nonlinear model can be applied to PMSMs.

Finally, the experiment verification was carried out. A machine test platform was built up. The collected machine test data were compared with the simulated machine performances. The simulation results show good agreement with the real machine curves for both the no-load and the loaded test results, which indicates that the proposed comprehensive PMSM mathematic model can be used to model and simulate the real machine incorporating the magnetic saturation effect.

\section{APPENDIX}

Detailed derivation of the structure saliency factors, as in (8) and (17), are provided. These factors are defined to enable the equivalent current composition, which is assumed to generate the total flux linkage. Originally, the total equivalent current vector could be expressed as in (31) nonlinear condition.

$$
\vec{i}_{t}^{*}=\vec{i}_{s}+K_{f} \vec{i}_{f}^{*}
$$

where $K_{f}$ is the composition factor.

Once the inductance on the $i_{s}$ direction is assumed as (32), $K_{f}$ is defined as (33).

$$
\begin{gathered}
L_{s}=\frac{L_{d}+L_{q}}{2}+\frac{L_{d}-L_{q}}{2} \cos 2 \rho \\
K_{f}=\frac{L_{d}}{\frac{L_{d}+L_{q}}{2}+\frac{L_{d}-L_{q}}{2} \cos 2 \rho}
\end{gathered}
$$

When the current vectors are projected on $\alpha-\beta$ or $d-q$ reference frame, the total equivalent current and the factors are then defined as

$$
\begin{gathered}
i_{t}^{*}=\sqrt{\left(i_{\alpha}^{*}\right)^{2}+\left(i_{\beta}^{*}\right)^{2}} \\
=\sqrt{\left[K_{\alpha}\left(i_{\alpha}+i_{f}^{*} \cos \theta\right)\right]^{2}+\left[K_{\beta}\left(i_{\beta}+i_{f}^{*} \sin \theta\right)\right]^{2}} \\
K_{\alpha}=\frac{\frac{L_{d}+L_{q}}{2}+\frac{L_{d}-L_{q}}{2} \cos 2 \theta}{\frac{L_{d}+L_{q}}{2}+\frac{L_{d}-L_{q}}{2} \cos 2 \rho} \\
K_{\beta}=\frac{\frac{L_{d}+L_{q}}{2}-\frac{L_{d}-L_{q}}{2} \cos 2 \theta}{\frac{L_{d}+L_{q}}{2}+\frac{L_{d}-L_{q}}{2} \cos 2 \rho} \\
i_{t}^{*}= \\
=\frac{\sqrt{\left(i_{d}^{*}\right)^{2}+\left(i_{q}^{*}\right)^{2}}}{K_{d}=} \\
K_{q}=\frac{\frac{\left.L_{d}+L_{q}\left(i_{d}+i_{f}^{*}\right)\right]^{2}+\left(K_{q} i_{q}\right)^{2}}{2}+\frac{L_{d}-L_{q}}{2} \cos 2 \rho}{\frac{L_{d}+L_{q}}{2}+\frac{L_{d}-L_{q}}{2} \cos 2 \rho}
\end{gathered}
$$

By substituting the $K_{\text {str }}$ definition, (35), (36), (38), and (39) could be simplified as in (8) and (17).

\section{REFERENCES}

[1] P. Pillay and R. Krishnan, "Control characteristics and speed controller design for a high performance permanent magnet synchronous motor drive,” IEEE Trans. Power Electron., vol. 5, no. 2, pp. 151-159, 1990.

[2] C. Lascu and A. M. Trzynadlowski, "Combining the principles of sliding mode, direct torque control, and space-vector modulation in a high-performance sensorless AC drive," IEEE Trans. Ind. Appl., vol. 40, no. 1, pp. 170-177, Jan./Feb. 2004.

[3] L. A. Cabrera, M. E. Elbuluk and D. S. Zinger, "Learning techniques to train neural networks as a state selector for inverter-fed induction machines using direct torque control," IEEE Trans. Power Electron., vol. 12, no. 5, pp. 788-799, Sept. 1997.

[4] S. Shinnaka, "New mirror-phase vector control for sensorless drive of permanent-magnet synchronous motor with pole saliency," IEEE Trans. Ind. Appl., vol. 40, no. 2, pp. 599-606, Mar./Apr. 2004.

[5] M. J. Corley and R. D. Lorenz, "Rotor position and velocity estimation for 
a salient-pole permanent-magnet synchronous machine at standstill and high speed," IEEE Trans. Ind. Appl., vol. 34, no. 4, pp. 784-789, Jul./Aug. 1998.

[6] J. H. Jang, S. K. Sul, J. I. Ha, K. Ide, and M. Sawamura, "Sensorless drive of surface-mounted permanent-magnet motor by high-frequency signal injection based on magnetic saliency," IEEE Trans. Ind. Appl., vol. 39, no. 4, pp. 1031-1039, Jul./Aug. 2003.

[7] S. Shinnaka, "A new speed-varying ellipse voltage injection method for sensorless drive of permanent-magnet synchronous motors with pole saliency-New PLL method using high-frequency current component multiplied signal," IEEE Trans. Ind. Appl., vol. 44, no. 3, pp. 777-788. May/Jun. 2008.

[8] C. V. Jones, The Unified Theory of Electrical Machines, Butterworth, London, 1967.

[9] B. Adkins and R. G. Harley, The General Theory of Alternating Current Machines, Application to Practical Problem, Chapman and Hall, London, 1975.

[10] David C. White and H. H. Woodson, Electromechanical Energy Conversion, John Wiley and Sons, 1959.

[11] J. E. Brown, K. P. Kovacs, and P. Vas, "A method of including the effects of main flux path saturation in the generalized equations of A.C. machines," IEEE Trans. Power App. Syst., vol. pas-102, no. 1, pp. 96-103, 1983.

[12] M. Alakula, and P. Vas, "Influence of saturation on the dynamic performance of vector-controlled salient-pole synchronous machines," in Proc. Int. Conf. Electrical Machines and Drives, pp. 298-302, 1989.

[13] L. Xu, X. Xu, T. A. Lipo, and D. W. Novotny, "Vector control of a synchronous reluctance motor including saturation and iron loss," IEEE Trans. Ind. Appl., vol. 27, no. 5, pp. 977-985, 1991.

[14] M. Alakula, and P. Vas, "Field-oriented control of saturated induction machines," IEEE Trans. Energy Convers., vol. 5, no. 1, pp. 218-224, 1990.

[15] P. J. Coussens, A. P. Van den Bossche, and J. A. Melkebeek, "Magnetizing current control strategies for nonlinear indirect field oriented control," in Proc. IEEE IAS Annu. Meeting, vol. 1, pp. 538-545, 1995.

[16] K. Boughrara, B. L. Chikouche, R. Ibtiouen, D. Zarko, and O. Touhami, "Analytical model of slotted air-gap surface mounted permanent-magnet synchronous motor with magnet bars magnetized in the shifting direction,” IEEE Trans. Magn., vol. 45, no. 2, pp. 747-758, Feb. 2009.

[17] J. A. Farooq, A. Djerdir, and A. Miraoui, "Analytical modeling approach to detect magnet defects in permanent-magnet brushless motors," IEEE Trans. Magn., vol. 44, no. 12, pp. 4599-4604, Dec. 2008.

[18] O. A. Mohammed, S. Liu, and Z. Liu, "Physical modeling of pm synchronous motors for integrated coupling with machine drives," IEEE Trans. Magn., vol. 41, no. 5, pp. 1628-1631, May 2005.

[19] Ji-Young Lee, Sang-Ho Lee, Geun-Ho Lee, Jung-Pyo Hong, and Jin Hur, "Determination of parameters considering magnetic nonlinearity in an interior permanent magnet synchronous motor," IEEE Trans. Magn., vol. 42, no. 4, pp. 1303-1306, Apr. 2006.

[20] Seung-Joo Kim, Hyung-Woo Lee, Kwang-Soo Kim, Jae-Nam Bae, Jong-Bin Im, Cherl-Jin Kim, and Ju Lee, “Torque ripple improvement for interior permanent magnet synchronous motor considering parameters with magnetic saturation,” IEEE Trans. Magn., vol. 45, no. 10, pp. 4720-4723, Oct. 2009.

[21] P. Vas, K. E. Hallenius, and J. E. Brown, "Cross-saturation in smooth-air-gap electrical machines," IEEE Trans. Energy Convers., vol. EC-1, no. 1, pp. 103-112, 1986.

[22] J. A. Melkebeek, and J. L. Willems, "Reciprocity relations for the mutual inductances between orthogonal axis windings in saturated salient-pole machines," IEEE Trans. Ind. Appl., vol. 26, no. 1, pp. 107-114, 1990.

[23] A. Vagati, M. Pastorelli, G. Franceschini, and F. Scapino, "Impact of cross saturation in synchronous reluctance motors of transverse-laminated type,” IEEE Trans. Ind. Appl., vol. 36, no. 4, pp. 1039-1046, Jul./Aug. 2000.

[24] K. J. Meessen, P. Thelin, J. Soulard, and E. A. Lomonova, "Inductance calculations of permanent-magnet synchronous machines including flux change and self- and cross-saturations," IEEE Trans. Magn., vol. 44, no. 10, pp. 2324-2331, Oct. 2008.

[25] Y. Li, Z. Q. Zhu, D. Howe, and C. M. Bingham, "Modeling of cross-coupling magnetic saturation in signal-injection-based sensorless control of permanent-magnet brushless ac motors," IEEE Trans. Magn., vol. 43, no. 6, pp. 2552-2554, Jun. 2007.

[26] J.A.A. Melkebeek, "Small signal dynamic modelling of saturated synchronous machines," Conf. Proc. Int. Conf. Ele. Mach. (ICEM), Lausanne, Switzerland, part 2, pp. 447-450, 18-21 Sept. 1984.

[27] F. M. L. L. De Belie, J. A. A. Melkebeek, L. Vandevelde, R. K. Boel, K. R. Geldhof, and T. J. Vyncke, "A nonlinear model for synchronous machines to describe high-frequency signal based position estimators," in Proc. IEEE Int. Conf. Electric Machines and Drives, pp. 696-703, 2005.

[28] Dong-Myung Lee, and Woo-Cheol Lee, "Analysis of relationship between abnormal current and position detection error in sensorless controller for interior permanent-magnet brushless dc motors," IEEE Trans. Magn., vol. 44, no. 8, pp. 2074-2081, Aug. 2008.

[29] P. Sergeant, F. De Belie, and J. Melkebeek, "Effect of rotor geometry and magnetic saturation in sensorless control of pm synchronous machines," IEEE Trans. Magn., vol. 45, no. 3, pp. 1756-1759, Mar. 2009.

[30] W. N. Fu, S. L. Ho, and Z. Zheng, "Design of position detection strategy of sensorless permanent magnet motors at standstill using transient finite-element analysis," IEEE Trans. Magn., vol. 45, no. 10, pp. 4668-4671, Oct. 2009.

[31] P. Cui, J. G. Zhu, Q. P. Ha, G. P. Hunter, and V. S. Ramsden, "Simulation of non-linear switched reluctance motor drive with PSIM," in Proceedings of the $5^{\text {th }}$ International Conference on Electrical Machines and Systems, Vol. 1, Aug. 2001, pp. 1061-1064.

[32] Y. Yan, J. G. Zhu, Y. Guo and H. Lu, "Modeling and simulation of direct torque controlled PMSM drive system incorporating structural and saturation saliencies," in Proc. IEEE IAS Annu. Meeting, Tampa, FL, Oct 2006, pp. 76-83.

[33] Y. Wang, J. G. Zhu, S. Wang, Y. Guo, and W. Xu, "Nonlinear magnetic model of surface mounted PM machines incorporating saturation saliency," IEEE Trans. Magn., vol. 45, no. 10, pp. 4684-4687, Oct. 2009. 